\section{The Use of Diagnostic Optical Tools to Assess Nitrogen Status and to Guide Fertilization of Vegetables}

\author{
Giorgio Gianquinto ${ }^{1,4}$, Francesco Orsini ${ }^{1}$, Paolo Sambo $^{2}$, \\ and Matilde Paino D'Urzo ${ }^{3}$
}

\begin{abstract}
AdDitIONAL INDEX WORDs. radiometers, chlorophyll meters, dynamic fertilization
Summary. Dynamic fertilization management is a way of bringing nutrients to the plant when they are crucial for its development. However, destructive measurements of crop nitrogen $(\mathrm{N})$ status are still too costly and time consuming to justify their use, and the implementation of methodologies based on non-destructive, quick, and easy to use tools for plant nutritional status monitoring appears as an appealing opportunity. Several optical tools for plant monitoring have been developed in recent years, and many studies have assessed their ability to discriminate plant $\mathbf{N}$ status. Such tools can measure at leaf level (hand-held optical instruments) or may consider the canopy of a plant or few plants (portable radiometers) or even measure areas, such as a field, a farm, or a region (aerial photography). The application of vegetation indices, which combine the readings at different wavelengths, may improve the reliability of the collected data, giving a more precise determination of the plant nutritional status. In this article, we report on the state of the art of the available optical tools for plant $\mathrm{N}$ status monitoring.
\end{abstract}

$\mathrm{N}$ itrogen is a major nutrient, which directly affects plant performances. Scarce $\mathrm{N}$ availability leads to both reduced growth and yield and early leaf senescence. Excess $\mathrm{N}$ may cause increased plant vigor, extending foliar growth and delaying harvest, as well as increased nitrate accumulation, susceptibility to diseases, and contributing to environmental contamination (Chen et al., 2004; Crawford, 1995). Thus, several studies of crop $\mathrm{N}$ requirement have been carried out (Kage et al., 2002; Redimbaugh and Campbell, 1991), and total $\mathrm{N}$ needs are now known for most cultivated species. All $\mathrm{N}$ used to be applied pre-plant or at the time of planting, but in recent years, many growers apply a portion of the $\mathrm{N}$ during crop growth, sidedressing, or through the irrigation water. However, to

This work was part of the workshop "Improvement in Nitrogen and Water Use Efficiency: Interest of Assessment Tools" held on 16 Sept. 2008 at the European Society for Agronomy Congress, Bologna, Italy.

${ }^{1}$ Department of Agro-Environmental Sciences and Technologies (DISTA), University of Bologna, Viale Fanin, 44, 40126 Bologna, Italy

${ }^{2}$ Department of Environmental Agronomy and Crop Science (DAAPV), University of Padova, via Università, 100, 35020 Legnaro, Padova, Italy

${ }^{3}$ KAUST-Plant Stress Genomics and Technology Research Center, King Abdullah University of Science and Technology, Thuwal 23955-6900, Saudi Arabia

${ }^{4}$ Corresponding author. E-mail: giorgio.gianquinto@ unibo.it. minimize $\mathrm{N}$ fertilizer costs and the loss of $\mathrm{N}$ and the subsequential soil and water pollution, $\mathrm{N}$ fertilizer should be given when its use is crucial for plant growth and yield (dynamic $\mathrm{N}$ management). Optimum $N$ fertilization requires a correct assessment of soil or crop $\mathrm{N}$ status. Tests, carried out before planting, determine the $\mathrm{N}$ for the crop and provide an estimate of the additional amount of $\mathrm{N}$ to be applied.

\section{Limits of the $\mathrm{N}$ balance sheet to guide fertilization}

The $\mathrm{N}$ balance sheet method was clearly illustrated in the early nineties, with the application of AZOBIL software (Machet et al., 1990) which provided recommendations for correct $\mathrm{N}$ management. The balance sheet is determined as follows:

$$
N \mathrm{f}=\mathrm{Nu}-(\mathrm{Np}+\mathrm{Nm}+\mathrm{Nr}+\mathrm{Ns}),
$$

where $\mathrm{Nf}$ is $\mathrm{N}$ supplied with fertilization; $\mathrm{Nu}$ is $\mathrm{N}$ taken up by the crop as estimated based on yield; $N p$ is calculated on $\mathrm{N}$ readily available in the soil at planting based on soil analysis; $\mathrm{Nm}$ is calculated on $\mathrm{N}$ mineralized from soil organic matter (SOM) with estimation based on SOM percent, carbon/N ratio of SOM, and soil texture; $\mathrm{Nr}$ is calculated from $\mathrm{N}$ mineralized from crop residues as an estimate based on the species and crop management, eventually considering incorporation; and $\mathrm{Ns}$ is calculated on supplemental $\mathrm{N}$ derived by organic $\mathrm{N}$ sources and distributed during the previous years, with estimation based on type, amount, and frequency of distribution.

This balance sheet is in fact extremely simplified and may present some estimating errors. For instance, it does not consider the inflow provided by atmospheric $\mathrm{N}$ or the outflow related to the $\mathrm{N}$ lost in leaching, volatilization, or denitrification. Moreover, these variables present a certain degree of uncertainty. The $\mathrm{N}$ applied with fertilization (which should corresponds to the fertilizer demand) is functional not only to the crop $\mathrm{N}$ uptake $[\mathrm{Nu}$ (calculated by yield is functionally related to climatic conditions)] but also to the soil supply (which depends on several variables and therein may fluctuate dramatically across years). On the other hand, soil analyses used for the determination of $\mathrm{N}$ to add as fertilizer are based on the measurement of the mineral $\mathrm{N}$ $(\mathrm{Np})$ content in the soil at the beginning of the crop season and on an estimation of $\mathrm{N}$ mineralization $(\mathrm{Nm}$, $\mathrm{Nr}$, and $\mathrm{Ns}$ ) during the growth period (pre-crop, organic matter content, organic fertilizer application, weather, etc.). However, these determinations require frequent soil tests that are expensive. Moreover, the mineralization rate of SOM depends upon temperature and soil moisture. Not including these occurrences causes imprecision in calculating $\mathrm{Nm}, \mathrm{Nr}$, and Ns. It is well reported that net $\mathrm{N}$ mineralization varies based on the preceding crops (this is the base for rotations), intercrops, green manure, and in general agricultural practices and management. As reported

\begin{tabular}{llll}
\hline $\begin{array}{l}\text { Units } \\
\text { To convert U.S. to SI, } \\
\text { multiply by }\end{array}$ & U.S. unit & SI unit & $\begin{array}{l}\text { To convert SI to U.S., } \\
\text { multiply by }\end{array}$ \\
\hline 0.3048 & $\mathrm{ft}$ & $\mathrm{m}$ & 3.2808 \\
2.54 & inch $(\mathrm{es})$ & $\mathrm{cm}$ & 0.3937 \\
1.1209 & $\mathrm{lb} / \mathrm{acre}$ & $\mathrm{kg} \cdot \mathrm{ha}^{-1}$ & 0.8922
\end{tabular}

\footnotetext{
Hhthedrogy : June $201121(3)$
} 
by Engels and Kuhlmann (1993), net $\mathrm{N}$ mineralization occurring in a soil varied dramatically as a consequence of repeated cropping, ranging from 25 to $97 \mathrm{~kg} \cdot \mathrm{ha}^{-1} \mathrm{~N}$ in potato (Solanum tuberosum) followed by potato, 27 to $99 \mathrm{~kg} \cdot \mathrm{ha}^{-1} \mathrm{~N}$ in cereals followed by cereals, 29 to $109 \mathrm{~kg} \cdot \mathrm{ha}^{-1} \mathrm{~N}$ in sugar beet (Beta vulgaris), and 33 to $163 \mathrm{~kg} \cdot \mathrm{ha}^{-1} \mathrm{~N}$ in leguminous crops.

Similarly, a long-term trial conducted in Rothamsted, United Kingdom, demonstrated that even in field with the same crop and a winter wheat (Triticum hybernum) cover crop the optimum $\mathrm{N}$ fertilizer rate varied from year to year, ranging from 176 to 240 $\mathrm{kg} \cdot \mathrm{ha}^{-1} \mathrm{~N}$ (Murphy et al., 2007).

The most effective and precise $\mathrm{N}$ fertilization is a function of the number of $\mathrm{N}$ applications. Experiments on summer cabbage (Brassica oleracea ssp. capitata) showed that at least six $\mathrm{N}$ applications were required to reduce errors and obtain a reliable indication of $\mathrm{N}$ application (He et al., 2007; Villora et al., 2003; Westerveld et al., 2003). Of course, the concept of effectiveness from a plant metabolic point of view does not correlate with the concept of economic effectiveness for the producer. In fact, small changes in $\mathrm{N}$ availability around the optimal point of crop-required $\mathrm{N}$ result in dramatic yield changes (Gianquinto et al., 2010). Other experiments carried out on corn (Zea mays) in Quebec highlighted that optimum $\mathrm{N}$ would significantly vary not only among seasons and within seasons (function of the region, the soils, and the crop management) but also among fields and even within fields (Tremblay et al., 2008).

This evidence suggests that $\mathrm{N}$ availability and timing are complex issues. The research on this topic was intense in the recent years (Shaffer, 2002) and is still ongoing. Consistently, several softwares were designed to simulate transport and transportation of nitrogen in soils and its uptake by plants.

Beside the $\mathrm{N}$ balance sheet method, other strategies are worth pursuing. A possible option is given by the web-based dynamic models, such as the Adapt-N (Melkonian, 2010). The Adapt-N provides in-season $\mathrm{N}$ recommendations for corn production based on simple soils, management, and crop inputs. It accounts for changes in soil $\mathrm{N}$ due to early season weather and adjusts the in-season $\mathrm{N}$ recommendations accordingly (Sogbedji et al., 2001, 2006).

A further recent development is the use of optical tools for monitoring the nutritional status of a crop at plant level.

\section{Monitoring crop nitrogen requirements through the assessment of plant nutritional status}

Plant measurements represent promising ways for monitoring crop nitrogen requirements throughout the growing season and for efficiently adjusting fertilization rates. Equipment and measurements should be precise, allow for quick results, and be relatively inexpensive. Some methods are based on measuring the concentration of nitrate in petiole, in stem ends, or in petiole sap. They have been widely investigated (e.g., Errebhi et al., 1998; Gardner and Jones, 1975; Porter and Sisson, 1991; Vitosh and Silva, 1996; Waterer, 1997), and guidelines for their use are available for crops, such as potato (Lewis and Love, 1994), broccoli [ B. oleracea ssp. italica (Kubota et al., 1997)], and bell pepper [Capsicum annum (Olsen and Lyons, 1994)]. Another tool that attracted interest more recently is based on deducing nitrogen concentration from measurements of leaf chlorophyll content. This approach was first implemented in Japan (Inada, 1963; Matsuzaki et al., 1980; Takebe et al., 1990), following the notion that a greener foliage color correlates positively with higher nitrogen content in the plant. Optical tools used to assess plant greenness can be divided into three main groups, according to their sampling unit: 1) hand-held optical instruments for measurement at individual leaf level, 2) portable radiometers for measurements at whole plant or plant canopy level, and 3) aerial photography for measurements of greater units, such as field(s), farm(s), or an entire area or region.

\section{Assessing the leaf nutritional status through hand-held optical instruments}

Hand-held optical tools are constituted by a clip provided with a photometer to obtain an indication of the chlorophyll content of the leaf.
Readings are collected from a sample of several leaves. These tools are mainly represented by the SPAD $502 \mathrm{CM}$ (Minolta, Osaka, Japan), the N-tester (Yara International, Oslo, Norway), and the newest Dualex and Multiplex (both produced by Force-A, Paris, France).

The SPAD and the N-tester provide a measure of leaf greenness, which is directly correlated with leaf chlorophyll and nitrogen contents. The two instruments differ in their sampling method: the SPAD provides every measurement individually, whereas the $\mathrm{N}$-tester gives a mean value of 30 readings. Moreover, their sampling unit have different scales but have been found to be correlated:

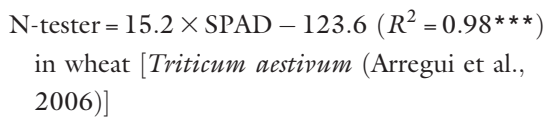

or

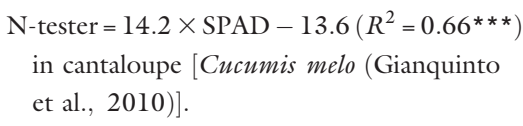

A linear correlation between the instruments' reading and both leaf chlorophyll and nitrogen contents was proved in several studies on corn (Blackmer and Schepers, 1995; Ma et al., 1996), rice [Oryza sativa (Johnkutty and Palaniappan, 1996)], soybean [Glycine $\max$ (Ma et al., 1995)], and cotton [Gossypium hirsutum (Wood et al., 1992; Wu et al., 1998)], although different values were found across the growing season in potato both for slope and intercepts (Gianquinto et al., 2004). The latter work in potato pointed out that the correlation with either chlorophyll or nitrogen content improved when expressed on a leaf area rather than with either fresh or dry weight basis. The application of both SPAD and $\mathrm{N}$-tester was successfully adopted on several crops, such as potato (Gianquinto et al., 2003a, 2003b, 2004), tomato [Solanum lycopersicum (Gianquinto et al., 2006)], cantaloupe (Gianquinto et al., 2010; Orsini et al., 2009), and friarielli [Brassica rapa ssp. sylvestris (De Pascale et al., 2008)].

Dualex and Multiplex instruments combine chlorophyll (greenness) readings with a simultaneous determination of polyphenol concentration, providing an even more accurate evaluation of plant nutritional status, as chlorophyll 
and polyphenol contents are linked to the crop nitrogen status (Cartelat et al., 2005; Cerovic et al., 2005). The application of the Dualex was tested on corn (Tremblay et al., 2007), wheat (Cartelat et al., 2005; Tremblay et al., 2010), and broccoli (Tremblay et al., 2009).

These instruments are relatively easy to use and allow for a great level of flexibility. They provide rapid and on-site indications of the nutritional status of the plants and therefore on the steps to follow to improve or maintain the most appropriate $\mathrm{N}$ fertilization regimen. They could find extensive application in controlled environment settings (greenhouses) and in open-field contexts, in particular for vegetable and ornamental crops.

In addition, leaf measurements can be pursued by using a common digital camera used on legumes (Wiwart et al., 2009) or a portable multispectral radiometer (Analytical Spectral Devices, Boulder, CO) used on corn (Zhao et al., 2003). However, these methods find greater application over larger sampling units, like those presented in the following two sections.

\section{Assessing the plant nutritional status through portable spectrometers}

Portable spectrometers are placed 1-3 $\mathrm{m}$ above the canopy to be measured and provide an estimation of the crop absorbance, measured as a difference between incident and reflected radiation. Again, the rationale is that the amount of radiation absorbed/ reflected by a plant is related to the color of its leaves and to their chlorophyll content related to the plant $\mathrm{N}$ status. Among these instruments, one of the most commonly used is the CROPSCAN MSR-87 Multispectral Radiometer (Cropscan, Rochester, $\mathrm{MN}$ ), which measures the reflectance of the canopy. It is constituted by 16 photo-sensors, half of them oriented upward (receiving solar radiation), whereas the remaining are facing downward (recording crop reflectance); a data logger with a remote; a telescopic support (usual height $\approx 180 \mathrm{~cm}$ ); and the operative software. Eight wavelengths (10-nm bandwidth centered specifically on $460,510,560,610$, $670,710,760$, and $810 \mathrm{~nm}$ ) are considered, and the instrument records the rate of reflected photo-radiation over the incident radiation to the crop.
Reading is extremely rapid (2-4 s), and the measure is provided for sampling time, angle of incident radiation, and global irradiation. The instrument provides best performances when solar incident angle and light conditions are ideal, thus when the sky appears clear and sunny, and no shaded portions are included in the sampling area. At present, its application has given promising results in several crops, such as tomato (Sambo et al., 2006b) and bell pepper (Sambo et al., 2006a). Another option is provided by the GreenSeeker handheld active spectroradiometer (NTech Industries, Ukiah, CA), which generates its own illumination source instead of using sun as a light source (minimum height above the canopy of 80 $\mathrm{cm})$. The GreenSeeker measures reflectance at two wavelengths, 670 and 780 $\mathrm{nm}$, respectively, and with a $60-\mathrm{cm}-$ wide field of view. The operator holds the GreenSeeker above the canopy and walks a specified distance (Bronson et al., 2005). Another option is the ImSpector V9 (Specim, Oulu, Finland), an imaging spectrograph component that works together with a standard matrix cameras. As for the GreenSeeker, the ImSpector measures the reflectance as related to the incident light provided by an artificial light-emitting source. Its application has been reported by Reyniers et al. (2004) on wheat. Finally, there are the portable spectrometers produced by Holland Scientific (Lincoln, NE), such as the Crop Circle ACS-430 and ACS-470, which provide reflectance measures over the crop canopy working on three measurement channels (e.g., 670, 730, and $780 \mathrm{~nm}$ ) (Solari et al., 2008).

The described radiometers usually provide real-time readings at different wavelengths. These values are therein correlated to vegetation indices, which are able to provide an indication of the plant nutritional status.

These spectrometers are more sophisticated than the first group considered and are more costly. They have many of the advantages and potentials of the tools in the previous group and they are relatively easy to use. As mentioned, canopy uniformity increases performances. The readings need conversion into a more practical "language" through vegetation indices, making this methodology dependent on the adoption and calculation of the most suitable index for any given species/ variety and context.

\section{Assessing the crop nutritional status through aerial photography}

Indications on the use of aerial images for the assessment of crop nutritional status have been provided by several authors. Remote sensing via aerial color and color infrared (CIR) photography has been used to survey vegetation health and density for both cultivated and wild flora. For instance, it has been used to detect $\mathrm{N}$ deficiencies in corn (Blackmer and Schepers, 1995; Scharf and Lory, 2002). According to these studies, color and/or CIR photographs could be used to predict $\mathrm{N}$ deficiency and corn $\mathrm{N}$ requirements. However, promising results from these studies were constrained by the need to remove pixels showing soil and the requirement that no $\mathrm{N}$ is applied before the photographs were taken (Scharf and Lory, 2002) or were focused on application of $\mathrm{N}$ at a later stage of crop growth (Sripada et al., 2005). In a more recent report by Sripada et al. (2006), the application was extended to the early stages of the crop season, with improved results. However, the uncovered portions of the soil still caused distortions in the readings. Therefore, correction factors to account for soil reflectance appeared to be crucial.

In this type of assessment, equipment and data interpretation require advanced skills. Aerial photography is a service provided by professional companies that could be contracted by producer associations or consortia, by extension agencies and by other institutions, both public and private.

This methodology, despite its limitations, could find specific applications for larger areas such as regional forest, wetland, crop, vineyard and be aimed at other agricultural analyses, especially considering that the same images could provide additional information on soil moisture content in the area analyzed, for uncovered portions of soil.

\section{The adoption of vegetation indices for the determination of plant nutritional status}

As anticipated, to use the values recorded by means of the different instruments, spectral vegetation indices 
(SVIs) are adopted, based on the relation between the low reflectance of the visible portion of the spectrum and the high reflectance of the invisible near-infrared radiation (NIR) (Bannari et al., 1995; Gitelson, 2004; Gitelson et al., 2005). Among SVIs, the most used are intrinsic vegetation indices (IVIs) and soil-adjusted vegetation indices [SAVIs (Huete, 1988; Rondeaux et al., 1996)].

Intrinsic vegetation indices usually are related to different wavelengths reflectance ratio (e.g., NIR/ GREEN or NIR/RED) (Gianquinto et al., 2006; Sambo et al., 2006b; Wiegand et al., 1990), where NIR is the reading at NIR radiation, and green and red are, respectively, the reading at the wavelength of the green and red colors. Alternatively, they may be based on more complex considerations: 1) normalized difference vegetation index based upon plant redness [NDVI $=($ NIR RED)/(NIR + RED) (Sellers, 1985; Sellers et al., 1994; Vouillot et al., 1998)], 2) relationship between the NDVI and greenness [NDVI-G = $($ NIR - GREEN $) /($ NIR + GREEN $)$ (Ma et al., 1996)], and 3) modified chlorophyll absorption in reflectance index $[\mathrm{MCARI}=(\mathrm{R} 700-\mathrm{RED})-0.2 \times$ $($ R700 - GREEN $) \times($ R700/RED $)$ (Daughtry et al., 2000)].

Soil-adjusted vegetation indices, though not widely used, are theoretically more reliable than the IVI. This is because the NIR reflectance is a poor estimator of groundcover at low cover values and has to be corrected for variations in soil background reflectance. Consequently, several other indices have been adopted: 1$)$ SAVI $=$ $(1+L) \times(\mathrm{NIR}-\mathrm{RED}) /(\mathrm{NIR}+\mathrm{RED}+$ L), with $L=0.5$ (Huete, 1988); 2) optimized SAVI [OSAVI $=(1+L) \times$ $(\mathrm{NIR}-\mathrm{RED}) /(\mathrm{NIR}+\mathrm{RED}+L)$, with $L=0.16$ being the optimized value (Rondeaux et al., 1996); and 3 ) transformed SAVI (TSAVI $=A \times(\mathrm{NIR}-$ $A \times \mathrm{RED}-B) /(\mathrm{RED}+A \times \mathrm{NIR}-A \times$ $B)$, with $A=1.086588029$ and $B=$ 4.037537356 (Baret et al., 1989), which is a vegetation index that minimizes soil brightness effects.

\section{Dynamic fertilization management using optical tools}

In the previous sections, correlations observed between the plant nutritional status and the readings of several optical tools were described. Consistently, it can be said that the correct assessment of the $\mathrm{N}$ required by a crop depends upon the availability of a reference or threshold. Below this threshold value the crop is responsive to additional fertilization, whereas above this point yields are unaffected or may be even significantly reduced. This translates into a linear-plateau function (Gianquinto et al., 2003b), where the readings of the optical tools (X) are related to the yield of the crop (Y) by the following equations:

$$
\begin{aligned}
& Y=a+b X, \text { for } X<X_{\mathrm{c}}, \\
& Y=c, \text { for } X \geq X_{\mathrm{c}} .
\end{aligned}
$$

The linear-plateau regression results from an iterative fitting procedure, which minimize residuals. In the equation, " $a$ " is the minimum yield achieved when no $\mathrm{N}$ is applied to the crop and " $b$ " is the linear coefficient of the function which correlates the increases in yield in response to additional $\mathrm{N}$ (which determines increases in the optical tool readings). $X_{\mathrm{c}}$ is the break point in the linear-plateau regression and describes the threshold value below which yield increases with increasing $\mathrm{N}$ rate. Although several studies addressed the determination of this threshold as an absolute measure, the pedo-climatic conditions in which the crop grows greatly affect the readings of the optical instruments used. The alternative provided by the adoption of "windows" or "spy plots" as reference appears the most promising strategy (Gianquinto et al., 2003a, 2010; Samborski et al., 2009): this procedure consists in applying a non-limiting $\mathrm{N}$ rate on a reference plot or strip (window) and comparing instruments' readings from the window to that from the field as such. Quite a few studies on the adoption of "spy plots" are reported in the literature, and the model applied to the data yielded in several experiments across Europe (Gianquinto et al., 2004) proved to be suitable in most cases. Again, scattering (defined as dispersion around a value or distortions) generally occurred when trials were carried out on soils with high nitrogen reserves, and for early sampling (Gianquinto et al., 2004), or when a too narrow range of $\mathrm{N}$ fertilizer rates were considered in the experiments. A bad point distribution around the regression line could be improved by plotting relative yield against modified, rather than original optical tool readings, such as the previously presented vegetation indices. Under these conditions, the adoption of dynamic fertilization allowed the dramatic reduction of $\mathrm{N}$ application (down to $30 \%$ to $60 \%$ in potato and $17 \%$ to $66 \%$ in cantaloupe) (Gianquinto et al., 2004, 2010).

\section{Conclusions}

The adoption of optical tools is a promising strategy for monitoring plant nutritional status and the management of $\mathrm{N}$ fertilization in crops. Different tools have been developed in recent years that can provide useful information at leaf, plant, field/farm, or regional levels. In the case of handheld optical tools and portable radiometers, the user has been made independent from time-consuming, repeated, expensive, and destructive sampling and testing. Still, there are limitations to the translation of the data into accurate assessments of the nutritional status of the crop. The adoption of combined readings at different wavelength and the application of vegetation indices may improve the reliability of the readings and their correlation with the crop nutritional status. However, more species-specific and contextspecific studies are needed, while the application of models for the management of $\mathrm{N}$ should remain a focus of further research activities.

\section{Literature cited}

Arregui, L.M., B. Lasa, A. Lafarga, I. Iraneta, E. Baroja, and M. Quemada. 2006. Evaluation of chlorophyll meters as tools for $\mathrm{N}$ fertilization in winter wheat under humid Mediterranean conditions. Eur. J. Agron. 24:140-148.

Bannari, A., M. Morin, F. Bonn, and A.R. Huete. 1995. A review of vegetation indices. Remote Sens. Rev. 13:95-120.

Baret, F., G. Guyot, and D. Major. 1989. TSAVI: A vegetation index which minimizes soil brightness effects on LAI and APAR estimation. Proc. XII Canadian Symp. Remote Sensing and Intl. Geoscience Remote Sensing Symp. '89, Vancouver, Canada, 1014 July 1989. p. 1355-1358.

Blackmer, T.M. and J.S. Schepers. 1995. Use of a chlorophyll meter to monitor nitrogen status and schedule fertigation for corn. J. Prod. Agr. 8:56-60. 
Bronson, K.F., J.D. Booker, J.W. Keeling, R.K. Boman, T.A. Wheeler, R.J. Lascano, and R.L. Nichols. 2005. Cotton canopy reflectance at landscape scale as affected by nitrogen fertilization. Agron. J. 97:654660.

Cartelat, A., Z.G. Cerovic, Y. Goulas, S. Meyer, C. Lelarge, J.L. Prioul, A. Barbottin, M.H. Jeuffroy, P. Gate, G. Agati, and I. Moya. 2005. Optically assessed contents of leaf polyphenolics and chlorophyll as indicators of nitrogen deficiency in wheat (Triticum aestivum L.). Field Crops Res. 91:35-49.

Cerovic, Z.G., A. Cartelat, Y. Goulas, and S. Meyer. 2005. In-the-field assessment of heat polyphenolics using the new optical leaf-clip Dualex, p. 243-250. In: J.V. Stafford (ed.). Precision agriculture '05. Wageningen Agricultural Publishers, Wageningen, The Netherlands.

Chen, B.M., Z.H. Wang, S.X. Li, G.X. Wang, H.X. Song, and X.N. Wang. 2004. Effects of nitrate supply on plant growth, nitrate accumulation, metabolic nitrate concentration and nitrate reductase activity in three leafy vegetables. Plant Sci. 167:635-643.

Crawford, N.M. 1995. Nitrate: Nutrient and signal for plant growth. Plant Cell $7: 859-868$.

Daughtry, C.S.T., C.T. Walthall, M.S. Kim, E.B. de Colstoun, and J.E. McMurtrey. 2000. Estimating corn leaf chlorophyll concentration from leaf and canopy reflectance. Remote Sens. Environ. 74:229239 .

De Pascale, S., A. Maggio, F. Orsini, A. Bottino, and G. Barbieri. 2008. Sulphur fertilization affects yield and quality in friarielli (Brassica rapa L. subsp. sylvestris L. Janch. var. esculenta Hort.) grown in a floating system. J. Hort. Sci. Biotechnol. 83:743-748.

Engels, T. and H. Kuhlmann. 1993. Effect of the rate of $\mathrm{N}$ fertilizer on apparent net mineralization of $\mathrm{N}$ during and after cultivation of cereal and sugar beet crops. J. Plant Nutr. Soil Sci. 156:149-154.

Errebhi, M., C.J. Rosen, and D.E. Birong. 1998. Calibration of a petiole sap nitrate test for irrigated 'Russet Burbank' potato. Commun. Soil Sci. Plant Anal. 29:23-35.

Gardner, B.R. and J.P. Jones. 1975. Petiole analysis and the nitrogen fertilization of Russet Burbank potatoes. Amer. Potato J. 52:195-200.

Gianquinto, G., J.P. Goffart, M. Olivier, G. Guarda, M. Colauzzi, L. Dalla Costa, G. Delle Vedove, J. Vos, and D.K.L. MacKerron. 2004. The use of hand-held chlorophyll meters as a tool to assess the nitrogen status and to guide nitrogen fertilization of potato crop. Potato Res. $47: 35-80$

Gianquinto, G., M. Fecondini, M. Mezzetti, and F. Orsini. 2010. Steering nitrogen fertilization by means of portable chlorophyll meter reduces nitrogen input and improves quality of fertigated cantaloupe (Cucumis melo L. var. cantalupensis Naud.). J. Sci. Food Agr. 90:482-493.

Gianquinto, G., P. Sambo, and D. Borsato. 2006. Determination of SPAD threshold values in order to optimise the nitrogen supply in processing tomato. Acta Hort. 700:159-166

Gianquinto, G., P. Sambo, and F. Pimpini. 2003a. The use of SPAD 502 chlorophyll meter for dynamically optimising the nitrogen supply in potato crop: First results. Acta Hort. 627:225-230.

Gianquinto, G., P. Sambo, and S. Bona. $2003 \mathrm{~b}$. The use of SPAD 502 chlorophyll meter for dynamically optimising the nitrogen supply in potato crop: A methodological approach. Acta Hort. 627:217-224.

Gitelson, A.A. 2004. Wide dynamic range vegetation index for remote quantification of biophysical characteristics of vegetation. J. Plant Physiol. 161:165-173.

Gitelson, A.A., A. Vina, V. Cigadanda, D.C. Rundquist, and T.J. Arkebauer. 2005. Remote estimation of canopy chlorophyll content in crops. Geophys. Res. Lett. 32:1-4.

He, C., X. Guo, W. Wang, and J. Wu. 2007. Study on the optimum $\mathrm{N}$ rates under spring cabbage-maize-winter cabbage rotation system. Agr. Sci. China 6:1322-1329.

Huete, A.R. 1988. A soil-adjusted vegetation index (SAVI). Remote Sens. Environ. 25:295-309.

Inada, K. 1963. Studies on a method for determining the deepness of green color and chlorophyll content of intact crop leaves and its practical applications. I. Principles of estimating the deepness of green color and chlorophyll content of whole leaves. Proc. Crop Sci. Soc. (Jpn.) 32:157-162.

Johnkutty, I. and S.P. Palaniappan. 1996. Use of chlorophyll meter for nitrogen management in lowland rice. Fert. Res. $45: 21-24$

Kage, H., C. Alt, and H. Stutzel. 2002. Nitrogen concentration of cauliflower organs as determined by organ size, $\mathrm{N}$ supply, and radiation environment. Plant Soil 246:201-209.

Kubota, A., T.L. Thompson, T.A. Doerge, and R.E. Godin. 1997. A petiole sap nitrate test for broccoli. J. Plant Nutr. 20:669-682.
Lewis, R.J. and S.L. Love. 1994. Potato genotypes differ in petiole nitrate-nitrogen concentrations over time. HortScience 29: 175-179.

Ma, B.L., M.J. Morrison, and H.D. Voldeng. 1995. Leaf greenness and photosynthetic rates in soybean. Crop Sci. 35:1411-1414

Ma, B.L., M.J. Morrison, and L.M. Dwyer. 1996. Canopy light reflectance and field greenness to assess nitrogen fertilization and yield of maize. Agron. J. 88:915-920.

Machet, J.M., P. Dubrulle, and P. Louis. 1990. AZOBIL: A computer program for fertilizer $\mathrm{N}$ recommendations based on a predictive balance sheet method, p. S2: 21-22. In: A. Scaife (ed.). Proc. I Congr. European Soc. Agron., 5-7 Dec. 1990, Paris.

Matsuzaki, A., K. Karia, H. Machida, and K. Tsunoda. 1980. Studies on growth control and nutritional diagnosis in rice plants. I. The nutritional diagnosis based on leaf color and the estimation of the number of spikelets per unit area. Jpn. J. Crop. Sci. 49:439-444.

Melkonian, J. 2010. Adapt-N A tool for calculating corn sidedress nitrogen rates. 30 Dec. 2010. <http://adapt-n.eas.cornell. edu/>.

Murphy, D.W., E.A. Stockdale, P.R. Poulton, T.W. Willison, and K.W.T. Goulding. 2007. Seasonal dynamics of carbon and nitrogen pools and fluxes under continuous arable and ley-arable rotations in a temperate environment. Eur. J. Soil Sci. 58:1410-1424.

Olsen, J.K. and D.J. Lyons. 1994. Petiole sap nitrate is better than total nitrogen in dried leaf for indicating nitrogen status and yield responsiveness of Capsicum in subtropical Australia. Aust. J. Exp. Agr. 34:835-843

Orsini, F., M. Mezzetti, and G. Gianquinto. 2009. The use of portable chlorophyll meter for the management of $\mathrm{N}$ fertilization in cantaloupe (Cucumis melo L.) grown under transparent polyethylene low tunnels. Acta Hort. 807:333-340.

Porter, G.A. and J.A. Sisson. 1991. Petiole nitrate content of Maine-grown Russet Burbank and Shepody potatoes in response to varying nitrogen rate. Amer. Potato J. 68:493-505

Redimbaugh, M.G. and W.H. Campbell. 1991. Higher plant responses to environmental nitrate. Physiol. Plant. 82:640650 .

Reyniers, M., E. Vrindts, and J. De Baerdemaeker. 2004. Optical measurement of crop cover for yield prediction of wheat. Biosystems Eng. 89:383-394. 
Rondeaux, G., M. Steven, and F. Baret. 1996. Optimization of soil-adjusted vegetation indices. Remote Sens. Environ. 55:95-107.

Sambo, P., D. Borsato, and G. Gianquinto. 2006a. Effect of nitrogen fertilization on yield and canopy reflectance of pepper (Capsicum annuum). HortScience 41:871 (abstr.).

Sambo, P., G. Gianquinto, and V. Forte. 2006b. Are optical tools suitable to manage phosphate and potassium fertigation in tomato crops? HortScience 4l: 1006 (abstr.).

Samborski, S.M., N. Tremblay, and E. Fallon. 2009. Strategies to make use of plant sensors-based diagnostic information for nitrogen recommendations. Agron. J. 101:800-816.

Scharf, P.C. and J.A. Lory. 2002. Calibrating corn color from aerial photographs to predict sidedress nitrogen need. Agron. J. 94:397-404

Sellers, P.J. 1985. Canopy reflectance, photosynthesis, and transpiration. Intl. J. Remote Sens. 6:1335-1372.

Sellers, P.J., C.J. Tucker, G.J. Collatz, S.O. Las, C.O. Justice, and D.A. Dazlich. 1994. A global $1^{\circ}$ by $1^{\circ}$ NDVI data set for climate studies. II. The generation of global fields of terrestrial biophysical parameters from the NDVI. Intl. J. Remote Sens. 15:3519-3545.

Shaffer, M.J. 2002. Nitrogen modeling for soil management. J. Soil Water Conserv. 57:417-425.

Sogbedji, J.M., H.M. van Es, J. Melkonian, and R.R. Schindelbeck. 2006. Evaluation of the PNM model for simulating drain flow nitrate- $\mathrm{N}$ concentration under manure-fertilized maize. Plant Soil 282:343360 .

Sogbedji, J.M., H.M. van Es, S.D. Klausner, D.R. Bouldin, and W.J. Cox. 2001. Spatial and temporal processes affecting nitrogen availability at the landscape scale. Soil Tillage Res. 58:233-244.
Solari, F., J. Shanahan, R. Ferguson, J Schepers, and A. Gitelson. 2008. Active sensor reflectance measurements of corn nitrogen status and yield potential Agron. J. 100:571-579.

Sripada, R.P., R.W. Heiniger, J.G. White, and A.D. Meijer. 2006. Aerial color infrared photography for determining early in-season nitrogen requirements in corn. Agron. J. 98:968-977.

Sripada, R.P., R.W. Heiniger, J.G. White, and R. Weisz. 2005. Aerial color infrared photography for determining late-season nitrogen requirements in corn. Agron. J. 97:1443-1451.

Takebe, M., T. Yoneyama, K. Inada, and T. Murukami. 1990. Spectral reflectance ratio of rice canopy for estimating crop nitrogen status. Plant Soil 122:295-297.

Tremblay, N., É. Fortier, R. Mellgren, C. Bélec, and S. Jenni. 2009. The Dualex: A new tool to determine nitrogen sufficiency in broccoli. Acta Hort. 824:121-131.

Tremblay, N., Z. Wang, B.-L. Ma, C. Bélec, and P. Vigneault. 2008. A comparison of crop data measured by two commercial sensors for variable-rate nitrogen application. Precis. Agr. 10:145-161.

Tremblay, N., Z. Wang, and C. Bélec. 2007. Evaluation of the Dualex for the assessment of corn nitrogen status. J. Plant Nutr. 30:1355-1369.

Tremblay, N., Z. Wang, and C. Bélec. 2010. Performance of Dualex in spring wheat for crop nitrogen status assessment, yield prediction and estimation of soil nitrate content. J. Plant Nutr. 33:57-70.

Villora, G., D.A. Moreno, and L. Romero. 2003. Crop quality under adverse conditions: Importance of determining the nutritional status, p. 59-78. In: R. Dris, R. Niskanen, and S.M. Jain (eds.). Crop management and postharvest handling of horticultural products. Crop fertilization, nutrition and growth. Kluwer Academic Publishers, Dordrecht, The Netherlands.
Vitosh, M.L. and G.H. Silva. 1996. Factors affecting potato petiole sap nitrate tests. Commun. Soil Sci. Plant Anal. 27:1137-1152.

Vouillot, M.O., P. Huet, and P. Boissard. 1998. Early detection of $\mathrm{N}$ deficiency in a wheat crop using physiological and radiometric methods. Agronomie 18:117130.

Waterer, D. 1997. Petiole sap $\mathrm{NO}_{3}-\mathrm{N}$ testing as a method for monitoring nitrogen nutrition of potato crops. Can. J. Plant Sci. 77:273-278.

Westerveld, S.M., M.R. McDonald, A.W. McKeown, and C.D. Scott-Dupree. 2003. Optimum nitrogen fertilization of summer cabbage in Ontario. Acta Hort. 627:211215 .

Wiegand, C.L., A.H. Gerbermann, K.P. Gallo, B.L. Blad, and D. Dusek. 1990. Multisite analyses of spectral-biophysical data for corn. Remote Sens. Environ. 33:1-16.

Wiwart, M., G. Fordoński, K. ZukGołaszewska, and E. Suchowilska. 2009. Early diagnostics of macronutrient deficiencies in three legume species by color image analysis. Comput. Electron. Agr. 65:125-132.

Wood, C.W., P.W. Tracy, D.W. Reeves, and K.L. Edmisten. 1992. Determination of cotton nitrogen status with a hand-held chlorophyll meter. J. Plant Nutr. 15:14351448.

Wu, F.B., L.H. Wu, and F.H. Xu. 1998. Chlorophyll meter to predict nitrogen sidedress requirements for short-season cotton (Gossypium hirsutum L.). Field Crops Res. 56:309-314.

Zhao, D., K. Raja Reddy, V.G. Kakani, J.J. Read, and G.A. Carter. 2003. Corn (Zea mays L.) growth, leaf pigment concentration, photosynthesis and leaf hyperspectral reflectance properties as affected by nitrogen supply. Plant Soil 257:205217. 